\title{
A HISTÓRIA NO BRASIL IMPERIAL: A PRODUÇÃO HISTORIOGRÁFICA NA REVISTA DO INSTITUTO HISTÓRICO E GEOGRÁFICO BRASILEIRO (1839-1850).
}

\author{
History in Imperial Brazil: the historiographical \\ production profile in the Brazilian Historical and \\ Geographical Institute's Review (1839-1850).
}

\author{
Julio Bentivoglio*
}

\begin{abstract}
RESUMO
O presente artigo destina-se a analisar os textos publicados nos primeiros onze anos da Revista do Instituto Histórico e Geográfico Brasileiro, entre 1839 e 1850, a fim de traçar um perfil dos artigos publicados, conferindo maior ênfase nos estudos de caráter autoral, resultantes do trabalho de pesquisa para analisar a produção historiográfica registrada nas páginas daquele periódico, a fim de perscrutar a natureza dos estudos históricos no Brasil. Ele procura identificar os autores presentes nos primeiros anos do periódico, as temáticas mais visitadas, os recortes temporais e geográficos adotados, dentre outros aspectos, para compor uma físionomia da escrita da história Brasileira vinculada ao IHGB.
\end{abstract}

Palavras-chave: Historiografia Brasileira; Instituto Histórico e Geográfico Brasileiro; Revistas de História.

\begin{abstract}
This article aims to analyze the texts published in the first eleven years of the Brazilian Historical and Geographical Institute's

* Professor de Teoria da História no Departamento de História e no programa de pós-
\end{abstract} graduação em História da UFES. 
Review, between 1839 and 1850, to draw a profile of the published articles, with particular emphasis in authorial studies, resulting from work of research to examine the historiographical production pressed on the pages of that journal, in order to scrutinize the nature of historical studies in Brazil. It seeks to identify the authors present in the first years of the review, the most visited themes, the temporal and spatial clippings adopted, among other aspects, to compose a fisiognomy to the writing of history linked to IHGB.

Keywords: Brazilian Historiography, Historical and Geographical Brazilian Institute; History Reviews.

Muito já se escreveu sobre o lugar da história no Brasil no século XIX, tanto em obras clássicas como as de José Honório Rodrigues $^{1}$, quanto em autores que se consagraram ao discutir a questão da história e da formação da nação relacionando-as ao surgimento do Instituto Histórico e Geográfico Brasileiro (doravante IHGB $)^{2}$, como é o caso de Arno Wehling ${ }^{3}$, Manoel Luis Salgado Guimarães ${ }^{4}$, Lúcia Maria Paschoal Guimarães ${ }^{5}$ e Temístocles Cezar ${ }^{6}$.

1 RODRIGUES, José H. A pesquisa histórica no Brasil. São Paulo: Companhia Editora Nacional, 1969 e RODRIGUES, José Honório. Teoria da História do Brasil (Introdução metodológica). $5^{\text {a }}$ ed. São Paulo: Ed. Nacional, 1978.

2 Surgido em 21 de outubro de 1838, no interior da Sociedade Auxiliadora da Indústria Nacional por 27 sócios, dentre eles Januário da Cunha Barbosa e Raimundo Cunha Mattos, e tendo como patrono o imperador D. Pedro II, a criação do IHGB destinava-se a levantar fontes para se pesquisar, escrever e divulgar a história e a geografia do Brasil, reuniu, ao longo do tempo, em seus quadros os grandes nomes da política, das letras, do magistério e da magistratura brasileira.

3 WEHLING, Arno. As origens do Instituto Histórico e Geográfico Brasileiro. Revista do IHGB, 338, 7-16, 1983 e WEHLING, Arno. Estado, história, memória: Varnhagen e a construção da identidade nacional. Rio de Janeiro, Nova Fronteira, 1999.

4 GUIMARÃES, Manoel L. Salgado. História e Natureza em von Martius: esquadrinhando o Brasil para construir a nação. Manguinhos - História, Ciências, Saúde, v.II, p.391-413, 2000, e GUIMARÃES, Manoel L. Salgado. Nação e civilização nos trópicos: o Instituto Histórico e Geográfico Brasileiro e o Projeto de uma História Nacional. Estudos Históricos, n. 1, 1988.

5 GUIMARÃES, Lúcia M. Paschoal. Da Escola Palatina ao Silogeu. Instituto Histórico e Geográfico Brasileiro (1889-1938). Rio de Janeiro: Museu da República, 2007 e GUIMARÃES, Lúcia M. Paschoal. Debaixo da imediata proteção de Sua Majestade Imperial: o Instituto Histórico e Geográfico Brasileiro (1838-1889). Revista do IHGB, nº 388, jul./set.,1995.

6 CÉZAR, Temístocles. O poeta e o historiador. Southey e Varnhagen e a experiência historiográfica no Brasil do século XIX. História Unisinos, São Leopoldo, n. 3, v. 11, set./dez., p. 306-312, 2007 e CEZAR, Temístocles. Presentismo, memória e poesia. Noções da escrita da história no Brasil oitocentista. In: PESAVENTO, Sandra J. (org.) Escrita, linguagem, objetos. Leituras de História Cultural. Bauru/São Paulo: Edusc, 2004. 
Recentemente novos estudos passaram a contemplar outras questões ${ }^{7}$ de modo que, neste longo percurso que vai da fundação do IHGB em 1838 até o presente muitos aspectos significativos já foram escrutinados. Destaca-se nestes estudos uma leitura política daquela escrita da história. Ou seja, historiadores e sua produção são analisados ora à luz de suas orientações político-partidárias, ora em sua relação com o governo imperial. Em todos eles uma chave interpretativa parece repetir-se: a fundação de uma história para a nação. Para Rodrigo Turin,

A busca da historicidade da nação implicava, em primeiro lugar, a delimitação dos procedimentos técnicos necessários para tal tarefa. Nesse sentido, uma das diretrizes principais do IHGB era formalizar a pesquisa histórica, dando-lhe um viés programático. Como destacou José Honório Rodrigues, logo nos primeiros estatutos da instituição fixava-se claramente a finalidade de coligir, metodizar, publicar ou arquivar os documentos necessários para a história e geografia do Império do Brasil (TURIN, 2011, p.32)

Neste artigo, busca-se indicar outro caminho analítico possível, qual seja, o de pensar o processo de institucionalização da história no Brasil do século XIX não através de textos fundadores como os de Januário da Cunha Barbosa (1780-1846) ou de Francisco Adolpho Varnhagen (1816-1878), mas através da análise do perfil dos artigos publicados na Revista do Instituto Histórico e Geográfico Brasileiro, cujo primeiro número saiu em 1839, observando seu caráter mais geral a fim de construir uma fisionomia da pesquisa histórica estampada no principal veículo de disseminação da História

7 Como, por exemplo, TURIN, Rodrigo. Os antigos e a nação: algumas reflexões sobre os usos da antiguidade clássica no IHGB (1840-1860). L'Atelier du Centre de recherches historiques. Disponível em: <http://acrh.revues.org/index3748.html>. Acesso em 10 fev. 2014 e também SILVA, Taíse Tatiana Quadros da. A reescrita da tradição: a invenção historiográfica do documento na História Geral do Brasil de Francisco Adolfo de Varnhagen (1854-1857). Dissertação de mestrado em História. Rio de Janeiro, Universidade Federal do Rio de Janeiro, 2006. 
no Império em seus primeiros anos de existência ${ }^{8}$. Trabalho semelhante e de qualidade inquestionável já foi empreendido por Lúcia Guimarães ${ }^{9}$ embora esta autora tenha sublinhado outro recorte de análise: a memória da nação. Percebe-se que a revista tem sido muito utilizada como fonte em inúmeros estudos existentes, mas até agora muito pouco como objeto. Neste sentido há apenas o trabalho pioneiro de Edney Sanchez ${ }^{10}$ e alguns textos já clássicos como os de Vicente Tapajós ${ }^{11}$ e de Max Fleiuss ${ }^{12}$. Devo lembrar que a publicação foi sempre generosa em celebrar a sua própria história e a dos integrantes do Instituto Histórico e Geográfico Brasileiro em suas páginas.

Entre os diferentes instrumentos de institucionalização da História como um campo e uma atividade científica autônomos, o caminho editorial, especificamente voltado para os periódicos, revistas e jornais de História, ainda é uma seara pouco explorada pelos historiadores ${ }^{13}$. Está para ser feito um amplo estudo que possa deslindar o destino das publicações científicas voltadas para a história no Brasil. Afinal, além do mercado editorial e livresco, também a criação de museus, institutos históricos, academias científicas, cadeiras de história nas faculdades e nos colégios brasileiros ou o reconhecimento e a presença de historiadores em cargos do governo, dentre outros, são também instrumentos que atestam o processo de

8 É preciso lembrar que em 1838 além do IHGB também foi criado o Arquivo Público do Império que, na República, transformou-se no Arquivo Nacional e, no ano seguinte apareceu a revista do IHGB, que expressam, indubitavelmente, marcos de institucionalização da pesquisa histórica no Brasil.

9 GUIMARÃES, Lúcia M. P. Op. Cit., 1995 e também em GUIMARÃES, Lúcia M. P. O periódico de uma société savante: a Revista do Instituto Histórico e Geográfico Brasileiro (18391889). ArtCultura, v.14, v.25, p.49-60, 2012.

10 Sanchez, Edney Christian Thomé. Revista do Instituto Histórico e Geográfico Brasileiro: um periódico na cidade letrada brasileira do século XIX. Dissertação de mestrado, Universidade Estadual de Campinas, 2003.

11 TAPAJÓS, Vicente. A Revista do Instituto Histórico e Geográfico Brasileiro. RIHGB, 147, n.351-352: 397-404, 747-751, abr./set. 1986. 1930.

12 FLEIUSS, Max. Páginas de História. $2^{\mathrm{a}}$ edição. Rio de Janeiro: Imprensa Nacional,

13 Raras publicações são devotadas à esta questão. Destaco em especial duas: STIEG, Margaret. The origin and development of scholarly historical periodicals. Tuscaloosa: University of Alabama Press, 1986 e PLUET-DESPATIN, Jacqueline, LEYMARIE, Michel et MOLLIER, JeanYves [org.]. La Belle époque des revues (1880-1914). Paris: Éditions de l'Institut Mémoires de l'Édition Contemporaine, 2002. 
institucionalização da História. Evidentemente que o processo de institucionalização do campo histórico no Brasil, não acompanhou a dinâmica vivida na França ou Alemanha durante o século XIX, onde por exemplo começaram a surgir seminários específicos devotados à história, como o de Leopold von Ranke em Berlim; tampouco se expressavam nesses três países uma compreensão similar do que seria a ciência histórica, coexistindo orientações ou modelos históricos distintos e multifacetados, como se verá adiante.

De qualquer modo, as revistas de história constituem um lugar social e um instrumento decisivo na institucionalização de um campo científico para a História, que se autonomiza enquanto saber, sendo ainda capaz de ilustrar uma determinada cartografia da pesquisa e da escrita da história ${ }^{14}$. No caso da Revista do Instituto Histórico e Geográfico Brasileiro (doravante RIHGB), embora destinada a redigir a história da nação, ela não se limitou a isso, de tal sorte que é preciso ver tanto as linhas de continuidade de uma escrita tradicional da história quanto algumas linhas de fuga que começam a flertar com concepções mais críticas e científicas. Bem como a presença de elementos ou agendas estranhas aos olhares atuais ${ }^{15}$. A seguir serão reunidos alguns dados dos primeiros onze anos daquela publicação, que permitem compreender um pouco mais a natureza dos estudos históricos no Brasil. De seu primeiro tomo, publicado em 1839 até o décimo segundo, publicado em 1850, é possível perceber os principais aspectos que caracterizariam o periódico ao longo do século XIX. Esse curto espaço de tempo ilumina um lugar privilegiado da escrita da história no Brasil, num momento de consolidação do regime monárquico no início do Segundo Reinado, que oscila entre duas orientações ou modelos: o compilatório e o disciplinar ${ }^{16}$. No primeiro, a preocupação maior é reproduzir estudos

14 Em que pese a influência de Pierre Bordieu ao pensar a constituição, relações de força e hierarquias existentes no interior de um campo e nos instrumentos que lhe são pertinentes, segue-se nesse ponto, às ponderações de: STIEG, Margaret. The origin and development of scholarly historical periodicals. Tuscaloosa: University of Alabama Press, 1986, p.7-11.

15 Incluem-se nessa rubrica, por exemplo, publicações e discussões a respeito da catequese ou a celebração de efemérides das monarquias lusa e brasileira.

16 Valdei Lopes de ARAÚJO destaca a existência de dois diferentes regimes de autonomia presentes na história produzida naquele momento em seu artigo Historiografia, nação e os regimes de autonomia na vida letrada no Império do Brasil. Varia História, vol.31, n.56, pp. 365 $400,2015$. 
anteriores, imitando seus estilos e visando um público de não especialistas. No segundo, há a emergência de uma história científica, mais autoral e voltada para experts ou para um público mais especializado. Nas palavras de Valdei Lopes de Araújo,

A revista trimestral, inclusive pelo seu formato mais próximo do livro, criava um espaço mais controlado para a produção histórica. Lance fundamental para produção de um espaço disciplinar, ou do ethos do historiador (Turin, 2009) ${ }^{17}$, a criação do IHGB, no entanto, não significou o fim das polêmicas ou o desaparecimento de modelos competitivos de escrita da história. De certa forma, os arranjos competitivos entre uma historiografia disciplinar e o que podemos chamar de "historiografias populares" é um traço de longa duração. ${ }^{18}$

Algumas perguntas surgem imediatamente da leitura da RIHGB. Que história conviria ao Brasil e aos editores da revista? Que tipo de textos deveriam ser publicados? Quais os objetos mais relevantes para o estudo do passado brasileiro? Que tipo de fontes era empregado para se estudar a história do Brasil? Qual a metodologia empregada na análise das fontes? Quais os temas mais visitados pelos historiadores brasileiros? Quais as áreas mais contempladas pela revista? Que períodos da história brasileira foram os mais estudados? Qual o peso dos estudos históricos ao lado dos geográficos na revista? Para as responder é preciso conhecer de perto algumas diretrizes do IHGB. E elas aparecem no prêmio criado em 1843,

uma medalha de ouro, no valor de $200 \$ 000$, rs., a quem apresentar o mais acertado - Plano de se escrever a historia antiga e moderna do Brasil, organizada com tal

17 TURIN, Rodrigo. Uma nobre, difícil e útil empresa: o ethos do historiador oitocentista. História da Historiografia, n. 2, p.12-28, mar. 2009.

18 ARAÚJO, Valdei L. de. artigo Historiografia, nação e os regimes de autonomia na vida letrada no Império do Brasil. Varia História, vol.31, n.56, 2015, p. 388. 
sistema que nela se compreendam as suas partes políticas, eclesiásticas e literária. ${ }^{19}$

Antes disso, no primeiro número da Revista, Januário da Cunha Barbosa já vinha imprimindo algumas reflexões que ilustravam as preocupações dos membros do Instituto Histórico e Geográfico Brasileiro, acerca dos princípios da publicação. Seu viés era, como sublinhou Manoel Guimarães, o de se escrever uma história para a nação, coligindo documentos importantes, artigos e memórias que pudessem compor um amplo painel da história do Brasil, mesmo antes do descobrimento e da colonização. De qualquer modo, o artigo de Carl F. von Martius (1794-1868) sagrou-se vencedor, ele que era membro da Academia de Ciências da Baviera tal como Leopold von Ranke, inclusive se conheciam. Nele defendia a escrita de uma história para o país que seria uma síntese do encontro das três raças que a compunham: brancos, negros e índios; superando um tipo de história que vinha sendo combatida na Alemanha, porque cronológica, filosófica e universalista; inspirada em Schiller ou em Hegel. Essa nova história era praticada por Ranke e seus discípulos, ela visava o particular, a compreensão dos nexos entre os eventos, o encontro com o espírito do povo e da nação. Uma história que buscava ser mais cientificamente orientada, pautada pela crítica das memórias, documentos e testemunhos ${ }^{20}$. Além da introdução dessa nova perspectiva, de fato pouco conhecida entre os brasileiros - mais afinados à tradição francesa que à alemã -, havia ainda o peso do modo de se conceber e escrever a história consoante o que era praticado na Academia de Ciências de Lisboa influenciada tanto pela tradição erudita que remontava ao Renascimento quanto pelo realismo de Alexandre Herculano que começava a inspirar alguns historiadores portugueses e brasileiros, além das referências e diálogos com as histórias produzidas pelos historiadores românticos franceses do século XIX, afinal, não poucos preconizavam que se

19 BARBOSA, Januário da Cunha. Como se deve escrever a História do Brasil?, RIHGB, n.7, 1843, p.562.

20 Cf. BENTIVOGLIO, Julio. Leopold von Ranke. In: MALERBA, Jurandir. Lições de História. Rio de Janeiro: FGV, 2010. 
deveria escrever a história não somente segundo a cor local, mas, sob o peso do beleletrismo de Chateaubriand, Thierry, Michelet e Cousin. O Dicionário de Bluteau revela que a história era descrita naquele tempo como "a narração de coisas memoráveis, que tem acontecido em algum lugar, em um certo tempo e com certas pessoas ou nações" 21 . E ainda citando Cícero, escreverá Bluteau que a "História é a testemunha do tempo, a luz da verdade, a vida da memória, a mestra da vida e a mensageira da Antiguidade",22. No Dicionário de Morais e Silva, História é a narração de sucessos civis, militares ou políticos. Ambos testemunham uma compreensão tradicional da história mais ou menos então corrente, visto não existirem no Brasil ou em Portugal manuais de teoria da história, de modo que os clássicos, como Heródoto, Tucídides, Políbio, Tácito e Cícero continuavam surgindo como índices de autoridade, expressando o ideal característico da história magistra vitae. $\mathrm{O}$ culto à erudição, aliás, era preservado no cultivo aos estudos clássicos, nos cursos jurídicos, na tribuna e na imprensa.

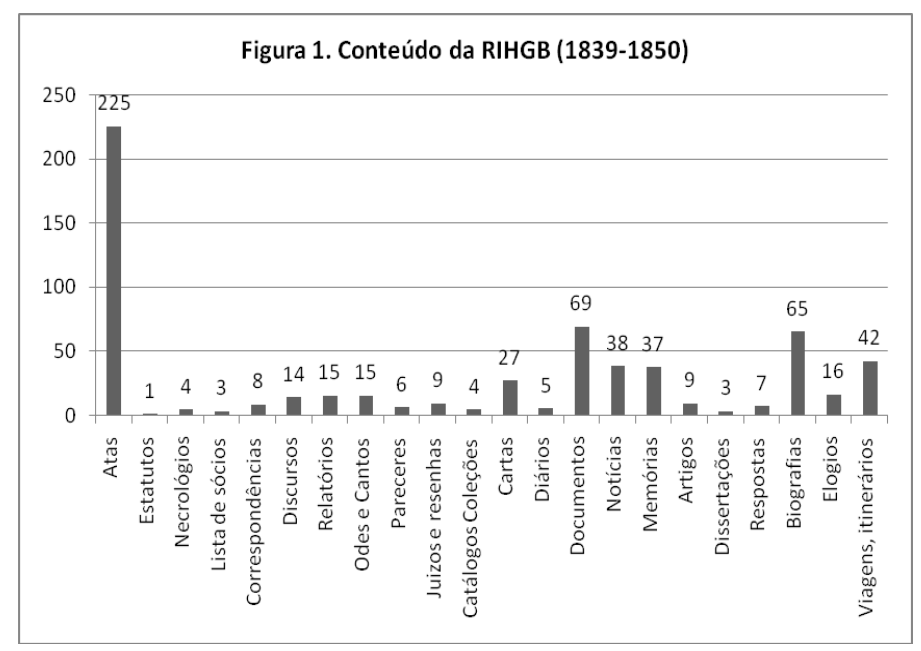

21 BLUTEAU, Raphael. Vocabulario portuguez \& latino: aulico, anatomico, architectonico ... Coimbra: Collegio das Artes da Companhia de Jesus, 1712-1728, v.4, p.39.

22 Ibidem, p.40. 
Contemplar o perfil geral do periódico (ver Figura 1) conduz a certas ponderações que restringem ou pelo menos minimizam essa compreensão. A RIHGB era uma revista trimestral que publicava textos em diferentes seções. Depois da publicação das atas do IHGB, cujas reuniões eram quinzenais perfazendo 225 no período recortado e que correspondem a $36 \%$ do que foi publicado, as duas maiores sessões da revista eram a de documentos $(11 \%)$ e a de biografias (10\%), seguidas pelos relatos e itinerários de viagens $(7 \%)$, pelas notícias e memórias, ambas com $6 \%$ cada. Artigos originais, respostas aos programas e dissertações que eram textos de maior caráter historiográfico e autoral - com exceção das biografias que eram numerosas e também possuíam esse caráter autoral - ocuparam um espaço menor no período analisado, como se pode observar na Figura 2. Lúcia Guimarães já havia apontado a heterogeneidade dos textos publicados na Revista, dividindo-os em 16 tipos $^{23}$. Na seção de notícias, por exemplo, era comum a publicação de traduções de livros e de documentos.

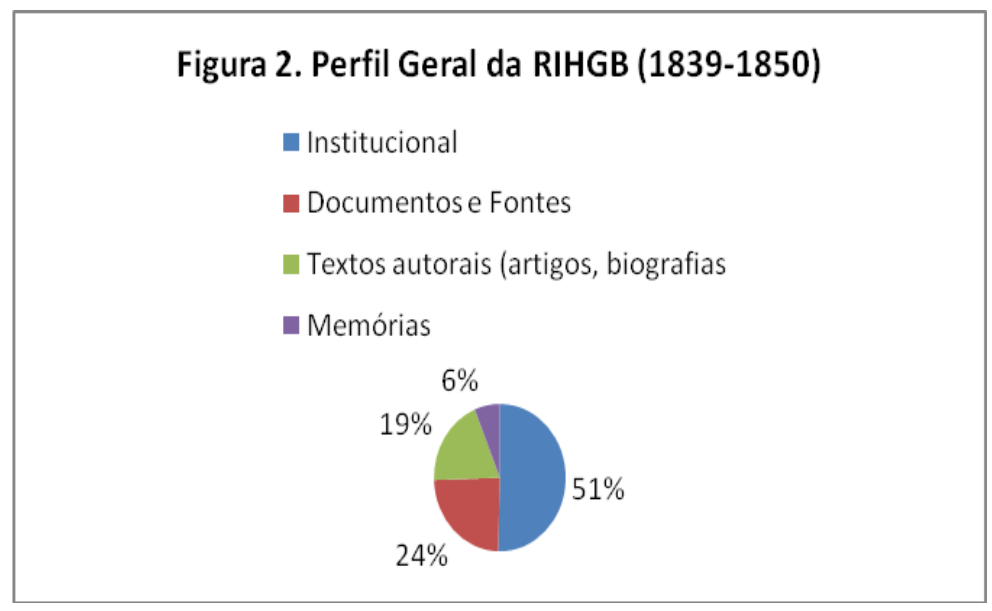

23 GUIMARÃES, Lucia M. P., Op. Cit., 1995, p.53. 
A princípio as seções não estavam padronizadas, documentos eram publicados ao lado de artigos históricos e "de textos referentes à administração da sociedade, como atas, relatórios e listagens de sócios" ${ }^{24}$. Mesmo a identificação do periódico era um tanto confusa, ora intitulado jornal, ora revista, somente em 1851 a nomenclatura revista trimestral se firma. Seu dístico latino Hoc facit, ut longos durent bene gesta per annos; et possint sera posteritate frui significa algo como fazer com que as boas ações durem muitos anos $e$ desfrutem de vida longa. No ano de 1889 era distribuída em 97 instituições nacionais e em 136 instituições estrangeiras. Até 1856 tinha tiragem de 500 exemplares e, devido às reedições, esse número deve ter dobrado a partir de 1876 , momento em que os tomos não receberam mais reedições ${ }^{25}$. De uma maneira geral se depreende que o espaço destinado à publicação institucional, dos atos administrativos e burocráticos representava mais da metade do que foi publicado.

Como se vê na Figura 2, 51\% dos textos publicados se referiam a questões institucionais, dedicando-se a registrar as reuniões do IHGB e suas atividades. Para Lúcia Guimarães, "as rotinas burocráticas acabaram por prevalecer sobre as atividades intelectuais" ${ }^{26}$. Em seguida, ocupando 1/4 da revista, aparece a publicação de documentos, notícias e fontes com 24\%. Textos autorais, como as respostas aos programas, os artigos e as dissertações ocupam 19\%, seguidos das memórias, com $6 \%$. Na Figura 3 está detalhado o espaço da documentação que foi publicada no periódico, 38\% referem-se à seção de Documentos, 69 foram publicados ao todo, em seguida surgem empatadas com $21 \%$ Notícias e Memórias - a maior parte delas constituem a publicação pelos sócios de memórias redigidas por terceiros - depois aparece com 15\% as Cartas - boa parte delas escritas pelos jesuítas durante o período colonial. Diários e Coleções vem por último, respectivamente com $3 \%$ e $2 \%$. Muitos diários foram publicados, mas se reportavam, sobretudo, a temas vinculados à Geografia, apenas cinco deles dizem 
respeito à História. $\mathrm{O}$ espaço destinado à documentação revela que se tratava de um "período da acumulação primitiva de capital arquivístico" 27 no interior da RIHGB, cujos sócios procuravam divulgar novas fontes para a pesquisa histórica.

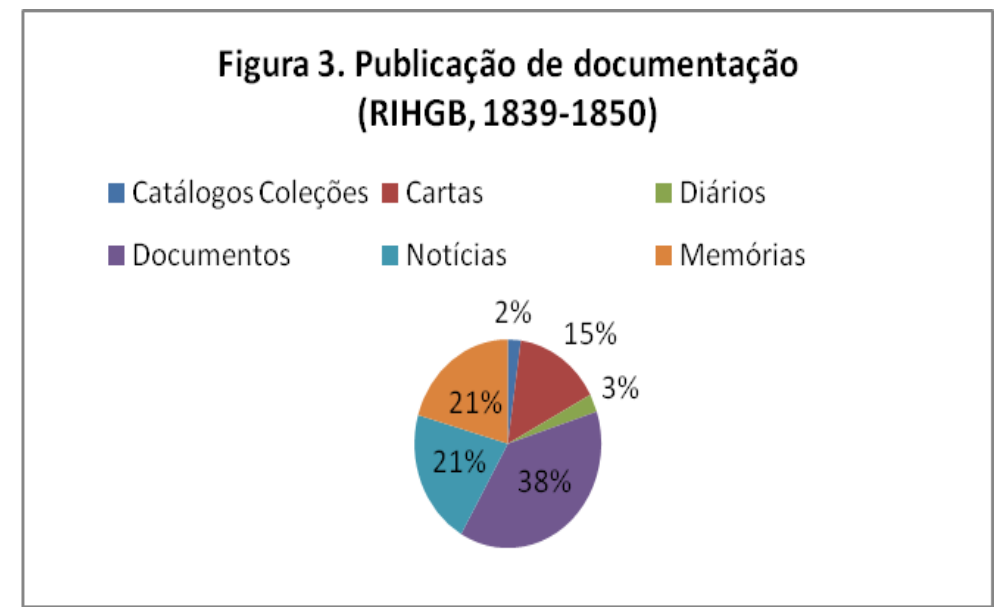

Na Figura 4 foram destacados os textos de caráter autoral, que correspondem a publicações originais redigidas pelos sócios para a revista. Neles se encontram artigos, memórias, biografias, pareceres, mas também juízos e resenhas sobre livros e artigos publicados. De longe as biografias aparecem como o tipo de artigo que mais se destaca na RIHGB, com $43 \%$ do total de textos autorais publicados. Em segundo lugar surgem as memórias com $24 \%$. Como já salientou Lúcia Guimarães, direcionados para a memória, os membros do IHGB pouco se ocuparam da História ${ }^{28}$. As memórias suplantavam a História, não por acaso o IHGB era conhecido como a "casa da

27 Para usar a expressão de CORBIN, Alain. Materiaux por um centenaire: le contenu de la Revue Historique et son évolution (1876-1972). Cahiers n.2, Institut d’Histoire de la Presse et de l’Opinion, 1979, p.163.

28 GUIMARAES, Lúcia M. P., Op. Cit., 1995, p.457. 
memória nacional"29. De certo modo, "a memória dos mortos [parecia servir] para suprir as carências da História escrita pelos vivos"30. Havia, portanto, um descompasso entre as metas perseguidas e a história efetivamente escrita, afinal essas memórias eram muitas vezes relatos de autoridades ou administradores, em sua grande maioria do período colonial. Em terceiro lugar aparecem os elogios, que também podem ser entendidos como um tipo particular de texto biográfico, mas destinado a tratar de membros do próprio IHGB falecidos naquele ano. Apenas nove artigos originais foram publicados e apenas três dissertações, que juntos perfazem apenas $9 \%$ do conjunto de textos autorais. Alguns dos critérios para a publicação dos artigos estão explícitos nos debates realizados nas sessões do Instituto Histórico e Geográfico Brasileiro, eles são sugeridos nos Programas sugeridos para pesquisa e nos Prêmios que foram sendo criados para incentivar novos estudos ou expedições geográficas.

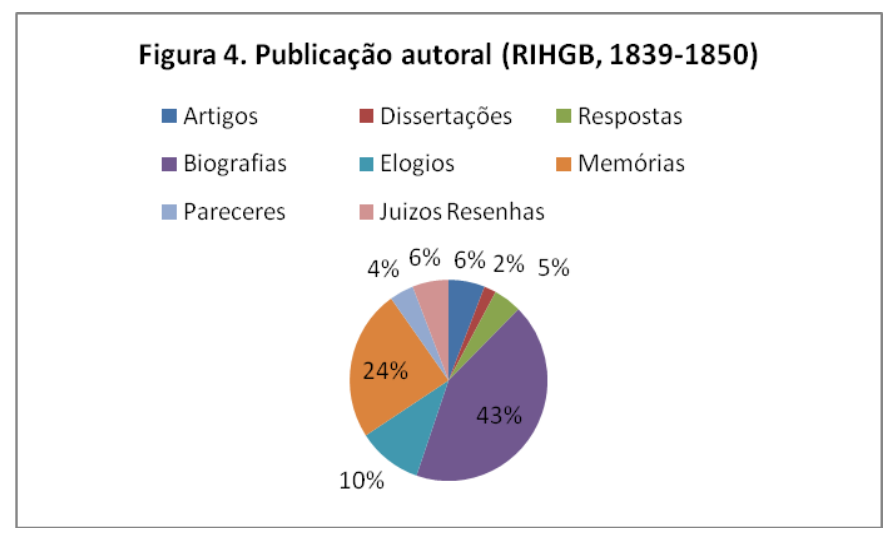

Dias,

A respeito dos trâmites para a publicação, assinala Fabiana

29 Cf. GUIMARÃES, Lúcia M. P. O periódico de uma société savante: a Revista do Instituto Histórico e Geográfico Brasileiro (1839-1889). ArtCultura, v.14, v.25, p.49-60, 2012.

30 Ibidem, p.567. 
De acordo com os Estatutos do IHGB, publicados em 1838, as comissões de geografia e de história incumbiam-se de receber as memórias, documentos e artigos, de dar o seu parecer indicando-os ou ao periódico, ou à publicação avulsa, ou ainda ao arquivo do Instituto. Tais comissões encarregavam-se, portanto, de julgar toda a gama de escritos apresentados, contemporâneos ou de época, assinados por sócios ou não. Dentre esse manancial havia dissertações originadas das provocações dos programas históricos, as quais, apesar de produzidas pelos agremiados, eram avaliadas com o mesmo rigor dispensado aos manuscritos enviados de toda a parte do território. não se podia falar de algo que prejudicasse pessoas vivas. ${ }^{31}$

\section{E prossegue a autora:}

Nesse sentido, no âmbito do IHGB, um contingente considerável de produções inéditas seria privado de chegar às páginas da Revista porque era desqualificado pelas comissões. Tais pareceres tomavam por base, invariavelmente, tanto o mérito acadêmico, quanto a conveniência da divulgação dos trabalhos. As dissertações apresentadas pelos sócios só seriam relevantes à publicação se coadunassem com os pressupostos da crítica documental e, ainda assim, se estivessem em acordo com o posicionamento político que se estabelecia como consensual. ${ }^{32}$

Depreende-se, portanto, que as dificuldades iniciais de captação de estudos originais ou de trabalhos que não ferissem orientações de caráter político da instituição fizeram com que a publicação de fontes ou a publicação de relatos de caráter burocrático

31 DIAS, Fabiana. Polifonia e consenso nas páginas da Revista do IHGB: a questão da mão de obra no processo de consolidação da nação. História da Historiografia, n.5, 2010, p.176.

32 Ibidem, p. 177. 
ou administrativo ocupassem um espaço muito maior. Apesar disso, a análise dos poucos artigos de história publicados nas páginas da RIGHB revela tanto o peso da herança retórica, adquirida na formação jurídica, no hábito do púlpito, da escrita para jornais e tribunas daquele império da eloqüência ${ }^{33}$, quanto o cultivo e a assimilação do tesouro dos antigos: no modo como os historiadores clássicos eram citados e incorporados por aquela escrita ${ }^{34}$. Para Maria da Glória Oliveira,

Entre os sócios do IHGB, a referência aos antigos assinala alguns balizamentos importantes no desdobramento das reflexões em torno da escrita da história. O que se percebe, sobretudo entre os fundadores do Instituto, é que a evocação de autores canônicos greco-latinos não se estabelece por meio de uma démarche historiográfica preocupada em compreender no que o passado difere do presente, mas se baseia em um jogo de identificações e analogias que, ao final, torna quase nula a distância entre os séculos. ${ }^{35}$

A despeito da presença dos clássicos, Temístocles Cezar reconhece não ter havido no Brasil uma querela entre antigos e modernos, que expressasse o rompimento ou a crise da história magistra vitae, mas, sim uma forte uma querela sobre os índios. Para Lúcia Guimarães a linha editorial até meados de 1850 era a de evitar a polêmica sobre a tradição colonial portuguesa. Valdei Araújo levanta ponto decisivo ao indicar que:

33 Ver a respeito SOUZA, Roberto Acízelo de. O império da eloqüência. Retórica e poética no Brasil oitocentista, Rio de Janeiro, EdUERJ/EdUFF, 1999.

34 Aspecto vivamente percebido por TURIN, R. A prudência dos antigos: figurações e apropriações da tradição clássica no Brasil oitocentista. O caso do Colégio Imperial Pedro II. Anos 90 (UFRGS. Impresso), v. 22, p. 299-320, 2015.

35 OLIVEIRA, Maria da Glória. Escrever vidas, narrar a história. A biografia como problema historiográfico no Brasil oitocentista. Rio de Janeiro: Editora FGV, 2011, p.54. 
A riqueza da historiografia oitocentista não pode ser encoberta por rótulos ingênuos como "tradicional", "não crítica" ou "positivista" (...). Esses rótulos, herança de uma história das idéias muito rígida, deveriam ser substituídos por objetos mais capazes de recuperar a complexidade dos fenômenos que nele se escondem, desde a formação de tradições de linguagens políticointelectuais e de conceitos histórico-sociais até a montagem de instituições e de ideologias. ${ }^{36}$

Michel de Certeau, em sua operação historiográfica destacou como a prática historiográfica expressa a conformação de regras e interditos para a escrita da história, de sorte que, a compreensão daquela atmosfera intelectual e o modo como escreviam, conferem relevo às práticas reconhecidas e autorizadas, identificada na admiração que havia pelos antigos entre os membros do IHGB, embora no século XIX já tivessem surgido parâmetros científicos que inspiravam novos modelos para a escrita da história na Inglaterra, na França e na Alemanha, que não passaram completamente despercebidos aos olhos dos autores brasileiros.

Herança, aprendizado, formação e inovação: tais palavras reforçam o caráter pedagógico das reuniões do IHGB, pois confraternizavam, disciplinavam e provocavam caminhos a serem trilhados pela instituição, vendo o que era útil e o que não seria conveniente à história do Brasil. Outro ponto decisivo a ser compreendido no conjunto dos artigos publicados diz respeito aos conceitos mais freqüentes, pois, como demonstra Koselleck, com cada conceito se estabelecem determinados horizontes, mas também limites para a experiência e para as histórias possíveis ${ }^{37}$. Aos poucos, as colaborações impressas ao longo dos números da RIHGB iam perfazendo um mosaico incompleto, mas cuja ambição seria fazer e reunir documentos e textos que abarcassem a história do Império e de

36 ARAÚJO, Valdei Lopes de. A experiência do tempo. Conceitos e Narrativas na Formação Nacional Brasileira (1813-1845). São Paulo: Hucitec, 2008, p.220.

37 KOSELLECK, Reinhart. Futuro passado. Contribuição à semântica dos tempos históricos. Rio de Janeiro: Contraponto, 2006, p.251-66. 
suas províncias, cujas partes se integrariam numa história única, uma verdadeira Monumenta brasiliae. Tratava-se de uma história que precisava romper com as experiências políticas do passado colonial e afirmar-se mediante a fundação de novos marcos, pacificando uma dada compreensão do presente. Ou seja, de uma história que purificasse a pátria, livrando-a de suas excessivas conotações portuguesas $^{38}$. Meta que a meu ver permaneceu inconclusa, pelo menos durante o período estudado.

Januário da Cunha propõe alguns dos marcos a serem perscrutados: a) notícias biográficas, b) manuscritos, c) notícias sobre os índios e seus costumes, d) descrição do comércio, e) relatos de fatos extraordinários, f) notícias sobre minerais, g) animais, h) território $^{39}$. E, de fato, uma triagem preliminar indica a presença marcante de estudos sobre os indígenas que são tão numerosos quanto os de natureza biográfica. Nas palavras do cônego e secretário perpétuo do Instituto:

a história reunirá estes materiais; a crítica os escolherá, segundo suas proporções; a cronologia os numerará depois de bem examinados os seus destinos afim de serem colocados regularmente pela filosofia em seus devido lugares, ligados em um corpo, em que possam ser admirados por sua justeza e compostura. ${ }^{40}$

Dar vida a beneméritos animou a seção: Biografias de Brasileiros Distintos, pois, como já anteriormente mencionado, as biografias constituíam um dos temas mais apreciados pela revista. Nos artigos a esse respeito, entrava em operação o famoso tribunal da posteridade. A existência das biografias mantinha em alguns casos

38 CÉZAR, Temístocles. Lição sobre a escrita da história. Historiografia e nação no Brasil do século XIX. Diálogos, DHI/UEM, v. 8, n. 1, 2004, p.14.

39 BARBOSA, Januário C. Lembrança do que devem procurar nas provincias os socios do Instituto Historico, para remetterem á sociedade central do Rio de Janeiro. RIHGB, tomo I, 1839, $3^{\mathrm{a}}$ edição (1908), p.52.

40 BARBOSA, Januário da Cunha. Relatório dos trabalhos do Instituto durante o quarto ano social. RIHGB, n.4, 1842 , p.6. 
uma incompreensão dos autores da distinção entre história e memória, algo apontado tanto por Lúcia Guimarães quanto por Maria da Glória Oliveira. Para esta última,

O culto dos grandes homens no contexto oitocentista implicava, portanto, a nacionalização da figura do herói, ou seja, os varões distintos seriam eleitos, antes de tudo, como grandes patriotas, valorosos por terem escrito uma página gloriosa da biografia da nação. ${ }^{41}$

Temístocles Cezar indica que tais retratos biográficos funcionariam como elementos de ligação. Nas palavras do historiador: "en premier lieu, ils font la connexion entre des contextes particuliers et des conjonctures plus larges; en second lieu, ils mettent en perspective les actes producteurs de la nationalité brésilienne depuis la découverte au XIX siècle, par le biais de la notion de modèle positif ou négatif. ${ }^{42} \mathrm{E}$ vale ressaltar que não precisavam ser exclusivamente brasileiros, afinal, o "Instituto publicará também as biographias de varões illustres, que posto não sejam brasileiros por nascimento, todavia o são por acções gloriosas, e por haverem passado grande parte de sua vida n'este paiz". 43

Francisco Adolfo de Varnhagen foi o maior contribuinte desta seção com 24 textos $(18,46 \%)$ e junto com ele destacam-se alguns outros nomes muito participativos: Januário da Cunha Barbosa, 11 biografias $(8,46 \%)$, Joaquim Caetano Fernandes Pinheiro com nove biografias (6,92\%), Manuel Duarte Moreira de Azevedo,

41 OLIVEIRA, Maria da Glória de, Op. Cit., p.286-7.

42 "Em primeiro lugar, eles fazem a conexão entre contextos específicos e conjuturas mais amplas; em segundo lugar, eles colocaram em perspectiva os atos produtores da nacionalidade brasileira desde a descoberta no século XIX, através da noção de modelo positivo negativo". CEZAR, Temístocles. L'écriture de l'histoire au Brésil au XIXe siècle. Essai sur une rhétorique de la nationalité. Le cas Varnhagen. Paris: EHESS, 2002 (História, Tese de Doutorado), t.1, p.288.

43 BARBOSA, Januário da Cunha, Op. Cit.,1842, p.82. 
oito biografias $(6,15 \%)$, Joaquim Norberto de Souza e Silva, sete biografias $(5,38 \%)$ e João Manuel Pereira da Silva, cinco $(3,84 \%)$. Juntos, estes seis escritores são responsáveis por metade dos perfis desta galeria. ${ }^{44}$

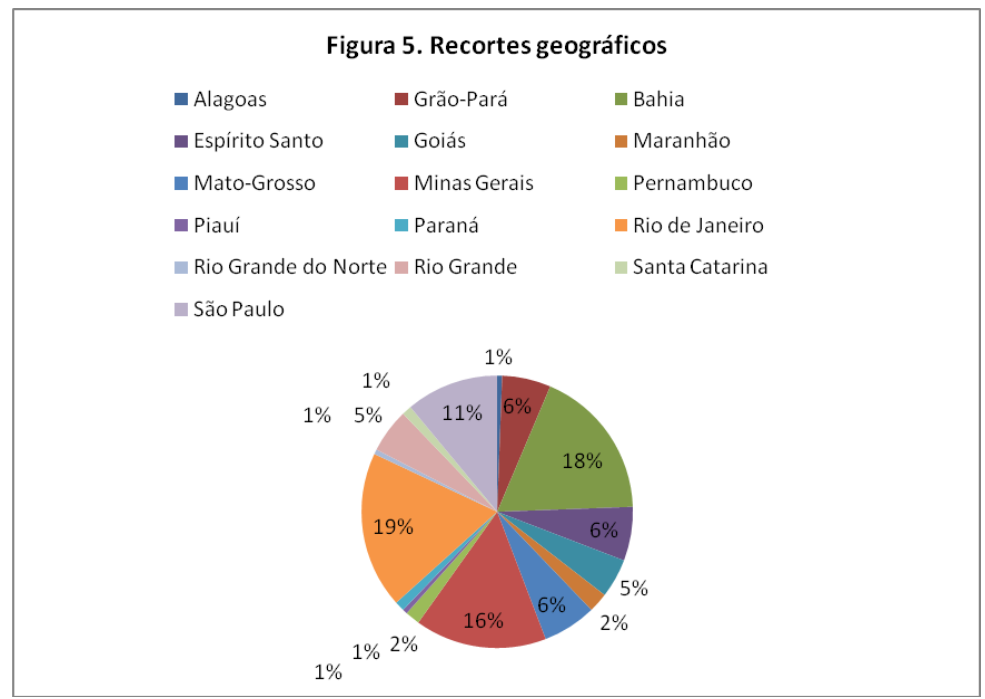

A Figura 5 traz o recorte geográfico dos textos publicados. Sua indicação neste breve estudo justifica-se pelo fato de que muitos autores relacionam o periódico à construção da história da nação ou da memória nacional, a despeito da complexidade do significado deste conceito no século XIX. Sabe-se da dificuldade do processo de construção de uma nação naquele contexto ${ }^{45}$, do processo gradual de interiorização da metrópole ${ }^{46}$. De qualquer modo, três províncias concentram a maior parte dos textos: Rio de Janeiro com 19\%, Bahia

44 SANCHEZ, Edney., Op. Cit., 2003, p.113.

45 JANCSÓ, I. \& PIMENTA, João Paulo G. Peças de um mosaico. In: MOTA, Carlos Guilherme (org). Viagem incompleta. São Paulo: Senac, 2000.

46 DIAS, Maria Odila L. da S. A interiorização da metrópole e outros estudos. São Paulo: Alameda, 2005. 
com $18 \%$ e Minas Gerais (16\%). Não somente eram também as províncias mais populosas, como também aquelas que detinham o maior número de vilas e cidades, bem como de membros no IHGB. Juntas ocupam 53\% do recorte geográfico encontrado. Em seguida surgem como referências constantes as províncias de São Paulo (11\%), Espírito Santo (6\%), Grão-Pará (6\%) e Mato Grosso (6\%). São Paulo, em muitas referências aos jesuítas no período colonial, Espírito Santo, Pará e Mato Grosso em textos sobre os índios, na maior parte das vezes. Piauí, Rio Grande do Norte e Alagoas aparecem apenas com uma publicação cada e são as províncias menos contempladas pelos textos da revista.

Compreender os recortes temporais dos artigos também possui um significado particular. Afinal, toda história tem um sentido, de modo que a periodização adquire um caráter político-pedagógico para o IHGB. Abreu e Lima, nesse sentido, havia proposto a seguinte periodização para a história do Brasil: a) descobrimento, primeiras explorações, estado físico do país; b) colonização; c) transição para o domínio estrangeiro; d) volta ao domínio pátrio, guerra dos holandeses; e) estado da colônia, melhoramentos, administração interna; f) estabelecimento da Corte no Brasil, administração do rei; g) Independência, administração do primeiro Império; h) Menoridade, administração da Regência, a maioridade. Em termos cronológicos teríamos: 1500-1530, 1531-1580, 1580-1640, 1640-1660, 1640-1808, 1808-1822, 1822-1831, 1831-1840, 1840- até o presente; ou seja, um recorte exclusivamente político. A respeito dessa obra de Abreu e Lima,

Varnhagen, em seu juízo apresentado ao IHGB, acusa o autor de ter se baseado exclusivamente na História do Brasil de Alphonse Beauchamp, conhecido plagiário do poeta e historiador inglês Robert Southey. Disso resultou, nas palavras de José Honório Rodrigues, uma "das mais violentas polêmicas da historiografia brasileira". A resposta de Abreu e Lima teria sido tão agressiva que o primeiro secretário, Januário da Cunha Barbosa, sugeriu 
ao Instituto a sua não publicação, pois ultrapassava os limites da decência. ${ }^{47}$

Essa periodização foi simplificada, logo depois, por Cunha Barbosa. Diz ele:

Sejam três as épocas da nossa história: na $1^{\circ}$ trata-se dos aborígenes ou autóctones; em $2^{\circ}$ compreendam-se as eras do descobrimento pelos portugueses, e da administração colonial; e a $3^{\circ}$ abranjam-se todos os conhecimentos nacionais desde o dia em que o povo brasileiro se constituiu soberano e independente, e abraçou um sistema de governo imperial, hereditário, constitucional e representativo. $^{48}$

Figura 6. Períodos contemplados pelos textos

" 1500-1822 =1822-1850 = Outros

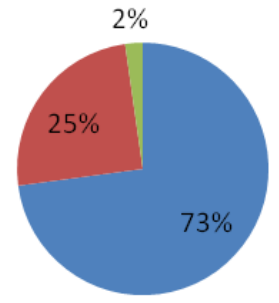

Na Figura 6 está relacionado o conjunto de textos por período histórico, observando-se a sugestão de Januário da Cunha Barbosa. Como se vê, apenas $25 \%$, ou $1 / 4$ das notícias, memórias, artigos, 
documentos e biografias retratavam a história recente do Império, conquanto a maioria, quase $3 / 4$ da revista se reportavam ao período colonial.

A leitura dos artigos autorais na Revista do Instituto revela a manutenção de um estreito diálogo com um modelo de história magistra vitae, que freqüentemente surge adaptado e, que raramente realiza sua revisão de maneira objetiva ou consciente. Penso haver uma relação clara deste aspecto com a adoção da agenda de von Martius e sua perspectiva política para a história brasileira, relacionada com as raças e a Independência. Além dessa agenda de von Martius é preciso incluir a colaboração tanto de Varnhagen quanto a de Tristão de Alencar, que compõem uma tríade fundamental para se compreender a matriz disciplinar para a escrita da história brasileira no século XIX que se constituiu em torno da revista e do Instituto. Segundo Maria da Glória Oliveira,

O uso da fórmula herdada dos antigos correspondia à experiência da constância da natureza humana dentro de um espaço temporal contínuo e, por conseguinte, à concepção de história como fonte de exemplos edificantes e lições morais fornecidas pelo passado, com a utilidade de instruir o presente. Contudo, na perspectiva de um regime de historicidade em que a plausibilidade da história como disciplina fundar-se-ia cada vez mais na capacidade de compreender e explicar os processos históricos na sua singularidade, o lugar-comum acerca da função magisterial da historiografia perderia muito de seu sentido. ${ }^{49}$ 


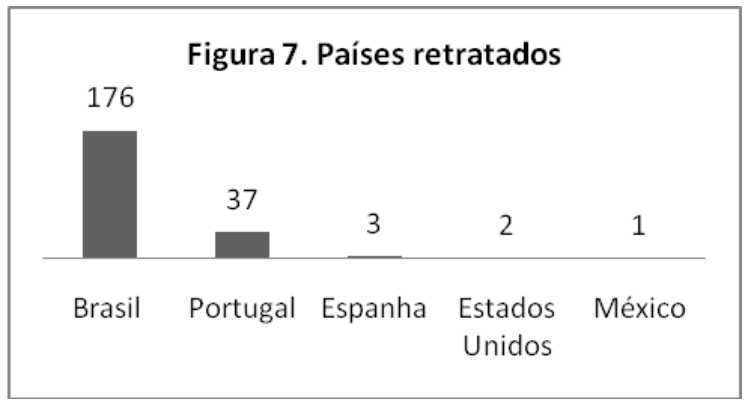

Uma leitura superficial do conjunto de artigos publicados indica que para além do Brasil o principal vetor das preocupações intelectuais oitocentistas referentes ao passado, outros países também foram citados (Figura 7). Embora o Brasil tenha ocupado 80\% dos textos publicados, Portugal surge com o expressivo percentual de $17 \%$, o que revela não somente os laços existentes entre as duas nações, como também a presença marcante da antiga Metrópole no interior dos estudos da historiografia na ex-colônia. Aliás, boa parte dos documentos ou fontes publicadas, bem como dos colaboradores da revista no período estudado, são portugueses. Nos primórdios do IHGB, para cada dois membros brasileiros havia ao menos um português de nascimento em seus quadros.

Isso não impedia, contudo, que se fizessem reprimendas no modo como a história do Brasil tinha e ainda vinha sendo escrita em Portugal:

Como será possível escrever uma história filosófica do povo do Brasil antes de levar ao cadinho da censura mais severa o imenso fardel de escritos inexatos, insultos, indigestos, absurdos e fabulosos, anteriores ao ano de 1822 em que unicamente se imprimia em Portugal, e raríssimas vezes no Brasil, aquilo que um governo desconfiado, uma inquisição intolerante, um Ordinário sem critério, uma mesa de comissão sobre a censura dos livros permitiam que fosse publicado? Como será possível escrever a história filosófica do Brasil tomando 
por farol os livros estrangeiros impressos antes da declaração da independência do império ? $^{50}$

Outro aspecto curioso é a presença freqüente de cronologias, anais, crônicas, memórias ao lado das histórias. E boa parte delas dedicada ao período colonial. Até meados de 1850 há uma enorme carência de artigos referentes à emancipação política, o que resulta, como assevera Lúcia Guimarães, de uma postura deliberada de "prudência política frente à conjuntura de incertezas do período regencial" 51 ou de sua proximidade temporal com o presente em que viviam. Por outro lado é possível pensar que o IHGB exigisse dos sócios, muitos deles tendo orientações e posicionamentos políticos diversos, postura mais suprapartidária e um maior compromisso com a imparcialidade, que de certo modo os impedia de escrever sobre o tempo presente, fazendo com que história fosse colocada, tal como na crítica exercida pelo Iluminismo analisada por Koselleck em Crítica e crise, no alto tribunal da razão, exigindo dos historiadores imperativos de ordem ética e moral. Algo explicitado, por exemplo, no parecer sobre o Elogio Histórico de José Bonifácio:

E se a severidade da critica ou a variedade do pensamento não permitte ainda que se fixe definitivamente a opinião que sobre os factos da independência deve ser formada; se é cedo para pronunciar-se a ultima palavra sobre assumptos que se prendem á nossa historia politica em tempos de tão agitadas comoções, seja-nos ao menos dado a nós, obreiros do porvir, juntar com desvelado esmero e accurada attenção todos os valiosos subsídios que a geração comtemporanea vai preparando para o soberbo monumento da historia da nossa pátria. A nós cabe a 
missão de honrar a memória dos grandes homens; à posteridade o encargo de julgal-os. ${ }^{52}$

Verdade e justiça, cumpre frisar, eram fundamentos do discurso jurídico no qual o documento entra como prova e como testemunho submetido à crítica para se encontrar a certeza e a revelação dos fatos. Sua presença no discurso historiográfico de então se afirma tendo em vista que muitos daqueles historiadores eram formados em ciências jurídicas; afinal, dos fundadores do IHGB, 16 eram egressos das faculdades de Direito.

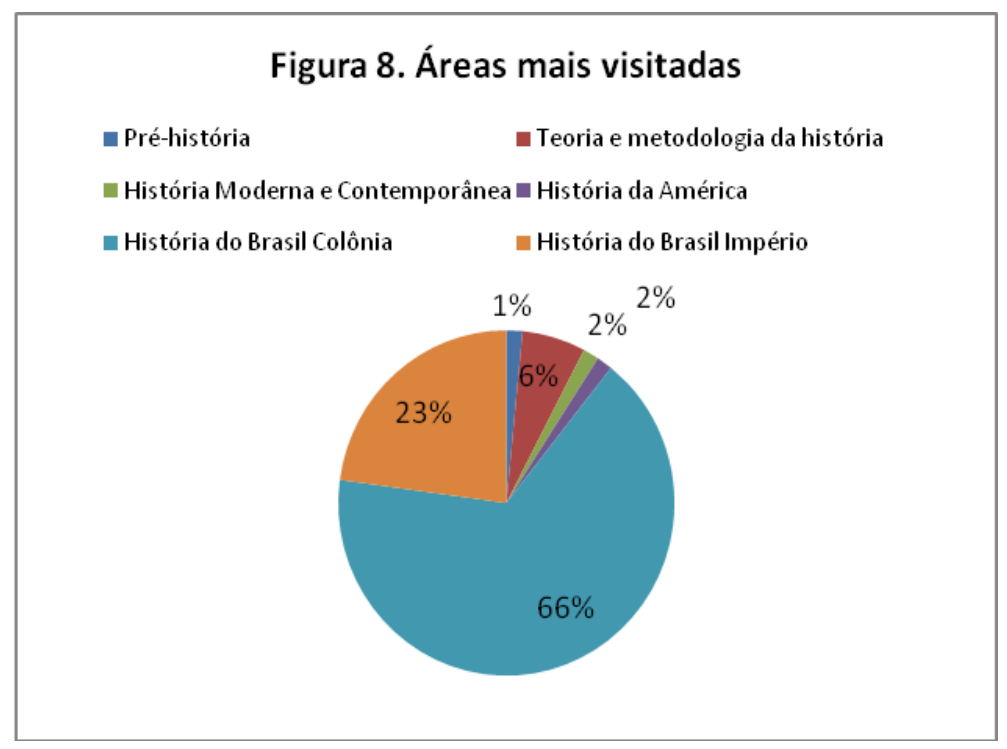

Em relação às memórias redigidas pelos sócios, algumas autorais, colocam em questão a afirmação de uma consciência moderna e científica do trabalho historiográfico. A história não surgia, pelo menos na maior parte dos textos da RIHGB, como um 
trabalho científico específico, tanto é que muitos sócios preferiam publicar memórias que estudos ou dissertações. E memórias significavam naquele contexto narrativas pessoais sobre coisas que se conheceu, escritos versando sobre temas políticos ou administrativos, que reuniam um conjunto de dados sobre determinado assunto ou acontecimento. ${ }^{53}$ As dissertações, por sua vez, eram "discursos didáticos sobre pontos políticos ou científicos" ${ }^{, 54}$.

Na Figura 8 estão indicadas as áreas do conhecimento mais visitadas na Revista entre 1839 e 1850 . Apenas três textos se referiam a achados arqueológicos e pré-históricos que juntos perfazem a área menos contemplada com $1 \%$. História do Brasil colonial corresponde a $2 / 3$ do total, ocupando $66 \%$ das publicações, somando 131 textos e artigos. Em seguida surgem os textos (45) referentes ao período imperial, totalizando 23\%. Publicações de caráter teóricometodológico ocupam um conjunto pequeno, mas expressivo de 12 dissertações e respostas, totalizando 6\%. Há na revista publicações sobre os Estados Unidos e México, agrupadas sob História da América que surge empatada com História Moderna e Contemporânea, perfazendo cada uma $2 \%$.

Em relação à teoria existem poucos, mas representativos textos, como o que traz a pequena citação abaixo, de Januário da Cunha Barbosa, a respeito das fontes que deveriam ser publicadas pela revista:

Os melhores materiais para escrever a historia do Brasil (e a de outros lugares), são os monumentos e as inscrições abertas em lâminas de pedra e metálicas; os diplomas legislativos, as cartas imperiais ou régias, os regulamentos ou regimentos, resoluções, avisos, provisões e patentes. Termos de posse de governadores, bispos, magistrados, oficiais municipais, e das outras classes de empregados públicos, e as cartas de sesmarias

53 Cf. BLUTEAU, Op. Cit.

54 Cf. SILVA, Antonio Moraes. Diccionario da lingua portugueza recompilado dos vocabularios impressos ate agora, e nesta segunda edição novamente emendado e muito acrescentado, por Antonio de Moraes Silva. Lisboa: Typographia Lacerdina, 1813. 
das terras concedidas aos mais antigos povoadores. Um crítico mui austero deve presidir ao exame destes monumentos; observar o talho da letra, a cor e o estado das tintas, confrontar as eras ou as cousas com pessoas, enfim desempenhar os deveres de bom paleógrafo e bom cronólogo. ${ }^{55}$

Em seguida, ele prossegue apontando outra etapa fundamental da operação historiográfica, a análise ou crítica do material:

A História reunirá estes materiais, coadjuvada pela Geografia; a crítica os acolherá, segundo suas proporções; a Cronologia os numerará depois de bem examinados os seus destinos, a fim de serem depois colocados regularmente pela filosofia em seus devidos lugares, ligados em um corpo, em que possam ser admirados por sua justeza e compostura (BARBOSA, 1842, p.6).

A citação acima revela o quanto no Brasil, como em Portugal, em relação ao método, gradualmente ocorria a emergência da crítica documental e um reconhecimento das ciências auxiliares. A Academia Real de História Portuguesa se ressentirá da emergência do método moderno, pois, de acordo com Joaquim Veríssimo Serrão, em sua História breve da Historiografia Portuguesa:

novos domínios [surgiram] com a valorização das chamadas ciências auxiliares. A genealogia, a Numismática, a Epigrafia, a história do Direito, a Bibliografia, a Diplomática, a Cronologia - [que] passam a constituir centros de interesse por parte dos 
investigadores procurando ultrapassar a noção de história política que fora seguida pelos antigos cronistas. ${ }^{56}$

Por fim, uma última palavra sobre os principais autores que publicaram na RIHGB, como não eram historiadores stricto sensu, pode-se seguir Roger Chartier e sua caracterização das gens de lettres da França, embora no Brasil sejam detectadas apenas duas categorias de literatos: uma formada por nobres e clérigos e outra ocupada pelos profissionais liberais como médicos, professores e advogados. Aqui inexistia o grupo de bibliotecários, arquivistas e tradutores como havia na França ou na Alemanha que publicavam nas revistas de história. Outra distinção importante é que no Brasil, a maior parte dos literatos e historiadores, senão todos, era de protegidos pelo Estado ou recebedores de benefícios (como Varnhagen), ou integrantes do governo imperial (como deputados, senadores, magistrados, etc.).

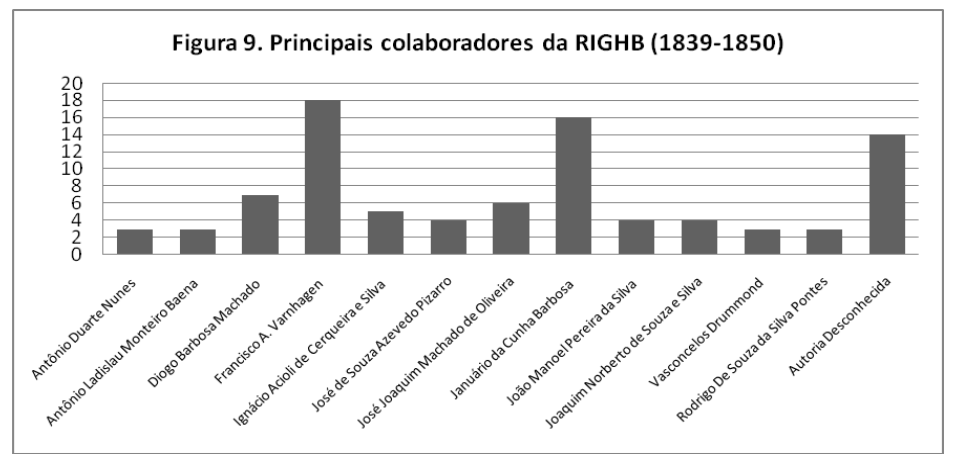

Na Figura 9 estão relacionados os autores que mais publicaram, entre 1839 e 1850, respostas aos programas, dissertações, biografias e memórias. Foram desprezados pareceres, elogios e necrológios para se privilegiar os textos que apresentavam resultados de estudos específicos sobre o passado brasileiro. Não por acaso Francisco Adolfo Varnhagen (1816-1878) aparece como o que mais 
publicou textos originais, num total de 18 colaborações, ele que é considerado o maior historiador brasileiro do século XIX, seguido por Januário Barbosa - cônego, fundador e secretário perpétuo do IHGB, com 16 e, logo depois, surge Diogo Barbosa Machado (1682-1772) com sete textos, membro da Academia Real de História Portuguesa. Deste último, sua enorme compilação, a Biblioteca Lusitana veio para o Brasil em 1808 e referenda o peso da tradição portuguesa na produção historiográfica impressa na Revista. Ignacio Accioli de Cerqueira e Silva (1808-1865), português naturalizado após participar ativamente da Independência brasileira e tido como um cronista maior do Império do Brasil autor de importantes estudos históricos, geográficos e etnográficos aparece com cinco colaborações. Com quatro publicações aparecem José de Souza Azevedo e Araújo Pizarro, monsenhor Pizarro (1753-1830), carioca, dos quais são publicados seus estudos sobre os jesuítas no Rio de Janeiro; João Manuel Pereira da Silva (1817-1898), que além de escritor e um dos fundadores do Romatismo brasileiro foi deputado geral e senador no Império entre 1888 e 1889 e, também, Joaquim Norberto de Souza e Silva (1820-1891), autor de um estudo sobre a Inconfidência Mineira e de diversas outras obras nos mais variados gêneros figuram também com conjunto expressivo de contribuições. Em linhas gerais eles ilustram os primeiros nomes que investiram com maior fôlego na produção de estudos históricos no Brasil, junto ao Instituto Histórico e Geográfico Brasileiro.

\section{Considerações finais}

Neste breve artigo procurou-se indicar algumas das principais características da escrita da história brasileira por meio de uma análise dos textos publicados na Revista do Instituto Histórico e Geográfico Brasileiro, entre 1839 e 1850. Estes primeiros 11 anos da publicação permitem conhecer um pouco os interesses, autores, recortes temporais, geográficos, temas e campos relacionados com a pesquisa histórica no Brasil, quando do início efetivo de seu processo 
de institucionalização, referendado na criação desta que é a primeira revista especializada de história brasileira. Ele procurou demonstrar a existência de dois modelos ou regimes de escrita, o compilatório relacionado com a história magistra vitae e o disciplinar ou científico mais próximo dos avanços da crítica documental em Portugal e na França. O surgimento de uma publicação voltada para estudos históricos e a incipiência deste saber no Brasil, ao lado das aproximações e distanciamentos dos modelos existentes explica a baixa incidência ou produção de artigos autorais e uma presença maior da publicação de fontes, memórias ou de textos burocráticos. Apesar do curto recorte temporal foi possível avaliar esses aspectos, mediante o diálogo desse rápido levantamento quantitativo com a farta bibliografia existente em torno do IHGB e de sua revista. Tabelas e gráficos permitiram demonstrar e ilustrar algumas das principais características da história produzida no Brasil durante aquele período. $\mathrm{O}$ intuito é que esse estudo preliminar seja acompanhado em breve por um levantamento mais sistemático que abarque todo o século XIX, oferecendo assim uma radiografia completa da produção historiográfica publicada nas páginas da revista do Instituto Histórico e Geográfico Brasileiro.

RECEBIDO EM: 09/05/2015 APROVADO EM: 17/11/2015 